for both undergraduate and graduate students from different disciplines.

\section{Measuring the Mind: \\ Conceptual Issues in Contemporary Psychometrics by Denny Borsboom, 2nd edition}

Paperback: 196 pages

Publisher: Cambridge University

Press; I edition in paperback

(I Jun 2009)

ISBN- 10: 052। 102847

ISBN-| 3: 978-052 | |0284|
This is the second edition of Measuring the Mind which was originally published in 2005. It is a book that is both philosophical and methodological. It addresses basic questions about measurement in psychology and psychiatry, such as whether it is possible to measure attributes like intelligence, personality and attitude. The book provides an indepth treatment of the philosophical foundations of widely used measurement models in psychology. In three chapters, classical test theory, latent variable theory and representational measurement theory are positioned in terms of the underlying philosophy of science. Each chapter also offers a very clear formal introduction to these theories. Special attention is devoted to the central concept of test validity and future directions to improve the theory and practice of psychological measurement are outlined. The book does not talk about genetics, but certainly introduces concepts that will be easily recognized by geneticists who work with genetic multivariate models.

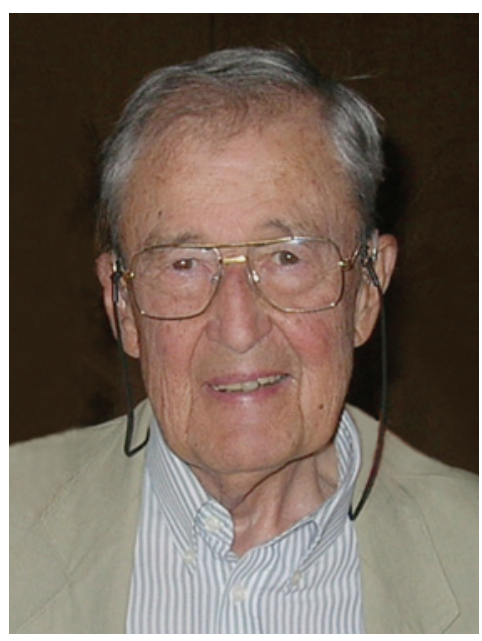

\title{
In Memorium
}

\section{Robert Maria Jozef Derom June 18, 1922 - July 29, 2009}

It is with great sadness that we record the death of Robert Derom on Wednesday, July 29, 2009, in a car accident nearby his home in Destelbergen, Belgium.

A relief for all his family is the very happy times they had celebrating his 60th wedding anniversary in the presence of all his children, grandchildren and great-grandchildren just one month beforehand. The funeral and burial were held at the village church of Destelbergen on 5 August, 2009.

Robert Derom was a great gemellologist, founder of the landmark East Flanders Twin Registry, and founding editor of this journal, Twin Research, in 1998. A full obituary will appear in a later issue. 